\title{
GAMBARAN KARIES YANG TIDAK DIRAWAT DENGAN KUALITAS HIDUP PADA SISWA/I KELAS VII SMP NEGERI 31 MEDAN
}

\author{
Asnita Bungaria Simaremare ${ }^{1}$, Rawati Siregar ${ }^{2}$ \\ Jurusan Keperawatan Gigi Poltekkes Kemenkes Medan
}

\begin{abstract}
Abstrak
Karies gigi merupakan suatu penyakit gigi dan mulut yang terdapat pada setiap orang tanpa memandang umur, bangsa ataupun keadaan ekonomi. Karbohidrat yang tertinggal di dalam mulut dan mikroorganisme merupakan penyebab dari karies gigi. Jika karies gigi tidak dirawat akan menyebabkan pulpitis, ulserasi, fistula, dan abces serta dapat berpengaruh pada kualitas hidup mencakup kehidupan sosial, emosional dan kesejahteraan. Jenis penelitian yang digunakan adalah penelitian secara deskriptif dengan metode survey yang bertujuan untuk mengetahui Gambaran Karies Yang Tidak Dirawat Dengan Kualitas Hidup Pada Siswa/i Kelas VII di SMP Negeri 31 Medan. Sampel dalam penelitian ini berjumlah 60 siswa/i. Pengambilan data pengetahuan siswa/i kelas VII diperoleh melalui kuesioner yang diisi langsung oleh siswa/i, sedangkan pemeriksaan status karies diperoleh dengan pemeriksaan langsung kerongga mulut siswa/i untuk mendapatkan status karies gigi ke rongga mulut yang tidak dirawat (DMF-T). Hasil penelitian tingkat kualitas hidup dengan karies yang tidak dirawat diperoleh data sebanyak 32 orang siswa/i (53\%) tingkat kualitas hidup sedang, 26 orang siswa/i (43\%) tingkat kualitas hidup baik, sedangkan 2 orang siswa/i (4\%) tingkat kualitas hidup buruk. Hasil pada penelitian mengenai status karies gigi tetap bahwa jumlah yang diperoleh DMF-T dengan rata-rata 2,4. Berdasarkan hasil penelitian didapat kesimpulan bahwa siswa/i kelas VII di SMP Negeri 31 Medan memiliki tingkat kualitas hidup sedang dengan status karies buruk. Untuk itu disarankan kepada siswa/i agar segera merawat giginya yang telah terkena karies.
\end{abstract}

Kata kunci : Karies yang tidak dirawat, Kualitas hidup

\section{PENDAHULUAN}

Menurut WHO, kesehatan adalah keadaan sempurna baik fisik, mental, maupun sosial, dan tidak hanya bebas dari penyakit dan cacat. Pembangunan kesehatan bertujuan meningkatkan kesadaran, kemauan, dan kemampuan hidup sehat bagi setiap orang agar terwujud derajat kesehatan yang optimal, maka individu masyarakat serta bangsa harus hidup sehat dan memiliki kemampuan untuk menjangkau pelayanan kesehatan yang bermutu (Notoatmodjo, 2007).

Kesehatan gigi dan mulut merupakan bagian yang terintegrasi dari kesehatan secara keseluruhan, sehingga perihal kesehatan gigi dan mulut perlu dibudayakan di seluruh lingkungan keluarga dan masyarakat (Tarwoto, dkk. 2012).

Masalah kesehatan gigi dan mulut di Indonesia dikatakan cukup tinggi. Berdasarkan Riset Kesehatan Dasar (RISKESDAS) tahun 2013, sebanyak 16 provinsi mempunyai prevalensi masalah kesehatan gigi dan mulut diatas angka nasional dan salah satu di Sumatera Utara sebesar $19,4 \%$. Penyakit yang sering diderita dan hampir semua penduduk Indonesia adalah karies gigi. Terjadi peningkatan karies gigi pada penduduk Indonesia dibandingkan tahun 2007 yaitu 43,3\% menjadi 53,3\% pada tahun 2013.
Kesehatan gigi dan mulut di Indonesia antara lain dapat dilihat dari hasil survei yang dilakukan oleh departemen kesehatan. Hasil studi morbiditas SKRTSURKESNAS 2001 menunjukkan bahwa dari 10 kelompok terbanyak yang dikeluhkan masyarakat, penyakit gigi dan mulut menduduki urutan pertama $(60 \%$ penduduk), sedangkan hasil SKRT tahun 1998 menunjukkan bahwa $62,4 \%$ penduduk terasa terganggu pekerjaan atau sekolahnya karena sakit gigi rata-rata 3,86 hari. Data terbaru riset kesehatan daerah tahun 2007 oleh Departemen Kesehatan RI menunjukkan bahwa penyakit gigi walaupun tidak menimbulkan kematian, tetapi dapat menurunkan produktivitas kerja (Tarwoto, dkk 2012).

Karies gigi adalah kerusakan jaringan keras gigi yang disebabkan oleh asam yang ada dalam karbohidrat melalui perantara mikroorganisme yang ada dalam saliva (Irma, 2013).

Penyakit karies gigi merupakan suatu proses kronis regresif yang dimulai dengan larutnya mineral email sebagai akibat terganggunya keseimbangan antara email dan sekelilingnya yang disebabkan oleh pembentukan asam microbial dari substrat sehingga timbul komponenkomponen organik yang akhirnya terjadi kavitas. Dimana prosesnya terjadi terus berjalan kebagian yang lebih dalam dari gigi sehingga membentuk lubang yang tidak dapat diperbaiki kembali oleh tubuh melalui proses penyembuhan, pada proses ini terjadi demineralisasi yang 
disebabkan oleh adanya interaksi kuman, karbohidrati pada permukaan gigi dan waktu (Margareta, 2012).

Karies yang tidak dirawat terjadi karena demineralisasi lapisan email, menyebabkan email menjadi rapuh. Jika karies gigi dibiarkan tidak dirawat, proses karies akan terus berlanjut sampai ke lapisan dentin dan pulpa gigi, apabila sudah mencapai pulpa gigi biasanya penderita mengeluh giginya terasa sakit. Jika tidak dilakukan perawatan, akan menyebabkan kematian pulpa, serta proses radang berlanjut sampai ke tulang alveolar. Beberapa masalah yang timbul pada karies yang tidak dirawat seperti pulpitis, ulserasi, fistula, dan abses (Nisa, 2016).

Menurut WHO (World Health Organization) kualitas hidup adalah suatu persepsi dari individu yang terdiri dari kemampuan fungsional, interaksi dalam masyarakat, kesehatan psikologi, kesehatan fisik, serta kepuasan hidup. Tercakup secara kompleks ada tidaknya kelainan patofisiologis, mengukur fungsi, dan penilaian individu atas kesehatannya, berdasarkan pernyataan tersebut kesehatan gigi dan mulut digambarkan dengan meneliti ada tidaknya penyakit, status fungsi fisik (pengunyahan), fungsi psikis (rasa malu), fungsi sosial (peranan sosial sehari-hari), kepuasan terhadap kesehatannya (Rianti, 2016). Berdasarkan latar belakang diatas maka peneliti ingin mengetahui gambaran karies yang tidak dirawat dengan kualitas hidup pada siswa/i kelas VII SMP Negeri 31 Medan Kelurahan Lau Cih Kecamatan Medan Tuntungan.

\section{Tujuan Penelitian}

Penelitian ini dilakukan bertujuan untuk mengetahui bagaimana gambaran karies yang tidak dirawat dengan kualitas hidup pada siswa/i kelas VII di SMP Negeri 31 Medan Kelurahan Lau Cih Kecamatan Medan Tuntungan.

\section{Manfaat Penelitian}

1. Untuk memberikan wawasan dan pengetahuan bagi siswa/siswi tentang karies yang tidak dirawat dengan kualitas hidup pada siswa/i di SMP Negeri 31 Medan Tuntungan Kelurahan Lau Cih.

2. Hasil penelitian ini dapat meningkatkan kesadaran siswa/i di SMP Negeri 31 Medan Tuntungan Kelurahan Lau Cih akan pentingnya merawat gigi sedini mungkin.

3. Dapat menjadi bahan masukan bagi pihak yang ingin melakukan penelitian sejenis atau penelitian lebih lanjut.

\section{METODE PENELITIAN}

\section{Jenis dan Desain Penelitian}

Jenis penelitian yang digunakan pada penelitian ini adalah penelitian deskriptif yang bertujuan untuk memperoleh Gambaran Karies Yang Tidak Dirawat Dengan Kualitas Hidup Pada Siswa/i Kelas VII SMP Negeri 31 Medan.

\section{Populasi dan Sampel Penelitian}

Populasi adalah keseluruhan objek penelitian atau objek yang diteliti (Notoatmodjo, 2010). Populasi dalam penelitian ini adalah seluruh Siswa/i Kelas VII SMP Negeri 31 Medan yang berjumlah 200 orang.

Sampel adalah sebagian dari jumlah dan karakteristik yang mewakili populasi (Setiadi, 2007). Sampel penelitian ini sebanyak 60 orang. Penentuan besar sampel digunakan rumus:

$$
\begin{aligned}
& \mathrm{n}=\frac{\mathrm{N}}{1+\mathrm{N}\left(\mathrm{d}^{2)}\right.} \\
& \mathrm{n}=\frac{200}{1+200\left(0,15^{2}\right)} \\
& \mathrm{n}=\frac{200}{1+200(0,0225)} \\
& \mathrm{n}=\frac{200}{1+2,25} \\
& \mathrm{n}=\frac{200}{3,25} \\
& \mathrm{n}=60
\end{aligned}
$$

Keterangan :

$\mathrm{N}=$ Besar Populasi

$\mathrm{n}=$ Besar Sampel

$\mathrm{d}=$ Tingkat Kepercayaan yang diinginkan

\section{HASIL DAN PEMBAHASAN}

\section{Hasil Penelitian}

Berdasarkan pengumpulan data mengenai gambaran karies yang tidak dirawat dengan kualitas hidup pada siswa/i kelas VII SMP Negeri 31 Medan diperoleh hasil penelitian sebagai berikut :

Tabel A.1

Distribusi Frekuensi Karies Yang Tidak Dirawat Pada Siswa/i Kelas VII SMP Negeri 31 Medan

\begin{tabular}{cccc}
$\begin{array}{c}\text { Karies } \\
\begin{array}{c}\text { Yang Tidak } \\
\text { Dirawat }\end{array}\end{array}$ & Jumlah & $\mathbf{n}$ & $\mathbf{r}$ \\
\hline Decay & 146 & 60 & 2,4 \\
\hline
\end{tabular}

Dari tabel A.1 diatas dapat diketahui bahwa 60 siswa/i kelas VII SMP Negeri 31 Medan diperoleh jumlah DMF-T sebanyak 146 dengan rata-rata karies gigi permanen 2,4 .

Tabel A.2

Distribusi Frekuensi Berdasarkan Kualitas Hidup Terhadap Karies Yang Tidak Dirawat Pada Siswa/i Kelas VII SMP Negeri 31 Medan

\begin{tabular}{ccc}
\hline $\begin{array}{c}\text { Kategori Kualitas } \\
\text { Hidup }\end{array}$ & n & $\mathbf{( \% )}$ \\
\hline Baik & 26 & $43 \%$ \\
Sedang & 32 & $53 \%$ \\
Buruk & 2 & $4 \%$ \\
\hline Total & $\mathbf{6 0}$ & $\mathbf{1 0 0}$ \\
\hline
\end{tabular}


Dari tabel A.2 diatas dapat diketahui bahwa dari 60 siswa/i kelas VII SMP Negeri 31 Medan, yang memiliki kualitas hidup sedang sebanyak 32 orang siswa (53\%), kualitas hidup baik 26 orang siswa (43\%), dan kualitas hidup buruk 2 orang siswa (4\%).

\section{PEMBAHASAN}

Berdasarkan tabel A.1 diatas hasil penelitian menunjukkan bahwa hampir sebagian siswa/i kelas VII SMP Negeri 31 Medan memiliki gigi berlubang, ini menunjukkan bahwa banyak siswa/i yang masih kurang menjaga kesehatan gigi dan mulutnya.

Berdasarkan hasil pemeriksaan, dapat diketahui bahwa 60 orang siswa/i diperoleh karies gigi permanen yang cukup tinggi dengan angka DMF-T 146 sehingga diperoleh rata-rata 2,4. Karies gigi ini terjadi karena siswa/i SMP Negeri 31 Medan kurang memperhatikan kesehatan gigi dan mulutnya, mempengaruhi perilaku dalam mencari pelayanan kesehatan gigi dan mulut, sehingga tidak ada upaya kesadaran untuk merawat kerusakan pada giginya. Dalam hal ini adanya peningkatan pengetahuan seseorang dalam bidang kesehatan gigi dan mulut, supaya diperoleh kesadaran dari siswa/i akan pentingnya upaya pemeliharaan kesehatan gigi dan mulut, upaya penanggulangannya, serta mampu menanamkan perilaku sehat sejak dini.

Menurut Tarigan R, (2012), karies gigi adalah penyakit jaringan gigi yang ditandai dengan kerusakan jaringan, dimulai dari permukaan gigi (ceruk, fisura, dan daerah interproksimal) meluas kearah pulpa. Karies gigi dapat dialami oleh setiap orang dan dapat timbul pada suatu permukaan gigi atau lebih, serta dapat meluas ke bagian yang lebih dalam dari gigi, misalnya dari email ke dentin atau ke pulpa.

Menurut Nisa, (2016), jika karies gigi dibiarkan tidak dirawat, proses karies akan terus berlanjut sampai ke lapisan dentin dan pulpa gigi, apabila sudah mencapai pulpa gigi biasanya penderita mengeluh giginya terasa sakit. Jika tidak dilakukan perawatan, akan menyebabkan kematian pulpa, serta proses radang terus berlanjut sampai ke tulang alveolar. Beberapa masalah akan timbul pada karies yang tidak dirawat apabila dibiarkan seperti pulpitis, ulserasi, fistula, dan abces. Dampak karies jika tidak dirawat akan mempengaruhi kualitas hidup meliputi gangguan pada dimensi keterbatasan fungsi, rasa sakit fisik, ketidaknyamanan psikis, ketidakmampuan fisik, ketidakmampuan psikis, ketidakmampuan sosial, dan hambatan lainnya. Dari penelitian ini dapat dilihat bahwa pada pengalaman karies gigi lebih tinggi dengan rata-rata DMF-T 2,4 yang mempunyai resiko lebih sering mengalami gangguan pada kualitas hidup. Hal ini disebabkan karena rasa sakit pada gigi akibat karies gigi yang tidak dirawat dan berdampak pada kesehatan rongga mulut yang buruk dapat berdampak negatif terhadap kualitas hidup remaja dan mengganggu ketidaknyamanan dan kesulitan misalnya mengucapkan kata-kata, tidak dapat mengecap rasa dengan baik, sakit yang sangat dirongga mulut, tidak nyaman mengunyah makanan, merasa khawatir, merasa tegang, diet (jumlah makanan yang dikonsumsi kurang memuaskan), terhenti saat makan, sulit merasa rileks, merasa malu, mudah tersinggung, sulit melakukan pekerjaan sehari-hari, hidup terasa kurang memuaskan, sama sekali tidak dapat berfungsi.

Berdasarkan data dari tabel A.2 diatas hasil penelitian yang telah dilakukan pada siswa/i kelas VII di SMP Negeri 31 Medan Kelurahan Lau Cih Kecamatan Medan Tuntungan dengan jumlah sampel 60 orang, diperoleh tingkat kualitas hidup terhadap karies yang tidak dirawat yaitu 32 orang siswa memiliki kualitas hidup sedang $(53 \%)$ mencapai kriteria sedang, itu dikarenakan karena pengetahuan siswa/i di SMP tersebut masih belum sepenuhnya memiliki kesadaran bahwa pentingnya menjaga kesehatan gigi dan mulut yang dapat mempengaruhi kualitas hidup mereka. Siswa yang memiliki kualitas hidup baik sebanyak 26 orang siswa (43\%) termasuk kriteria baik, ini berarti sebagian dari siswa/i tersebut mengetahui bahwa pentingnya menjaga kesehatan gigi dan mulut serta mempunyai kesadaran dari setiap individu bahwa pentingnya menerapkan hidup sehat sejak dini yang mempengaruhi kualitas hidup. Siswa yang memiliki kualitas hidup buruk sebanyak 2 orang siswa (4\%), dalam hal ini siswa tersebut tidak berperan penting dalam memiliki pengetahuan dalam halnya menjaga kesehatan gigi dan mulut yang berpengaruh pada kualitas hidup.

Menurut Notoatmodjo (2010), pengetahuan adalah hasil dari tahu dan ini terjadi setelah seseorang melakukan penginderaan terhadap suatu objek tertentu. Salah satu faktornya perilaku atau tindakan tentang kesehatan gigi dan mulut meliputi pengetahuan, sikap dan tindakan terhadap individu yang terdiri dari kemampuan fungsional, interaksi dalam masyarakat, kesehatan psikologi, kesehatan fisik, serta kepuasan hidup terhadap kesehatannya yang berkaitan dengan kesehatan gigi dan mulut. Dalam meningkatkan pengetahuan seseorang dalam bidang kesehatan gigi dan mulut diperoleh dari kesadaran setiap individu akan pentingnya pemeliharaan kesehatan gigi dan mulut. Pengetahuan tersebut mampu memperkenalkan kepada masyarakat tentang penyakitpenyakit gigi dan mulut, upaya penanggulangannya, serta terpenting adalah mampu menanamkan perilaku sejak dini.

\section{SIMPULAN DAN SARAN}

\section{Simpulan}

Hasil penelitian mengenai karies yang tidak dirawat dengan kualitas hidup pada siswa/i kelas VII SMP Negeri 31 Medan yang diperoleh maka simpulannya sebagai berikut :

1. Tingkat kualitas hidup terhadap karies yang tidak dirawat diperoleh data sebanyak 32 orang siswa (53\%) memiliki pengetahuan sedang, dalam hal ini siswa/i di SMP 31 Negeri Medan masih belum sepenuhnya memiliki kesadaran bahwa pentingnya menjaga kesehatan gigi dan mulut yang dapat mempengaruhi kualitas hidup mereka.

2. Untuk karies yang tidak dirawat pada gigi permanen diperoleh jumlah DMF-T 146 dan 
DMF-T rata-rata 2,4. Karies pada siswa/i di SMP Negeri 31 Medan masih cukup tinggi diakibatkan karena siswa/i tersebut tidak menjaga dan memperhatikan kesehatan gigi dan mulut mereka.

\section{Saran}

1. Diharapkan kepada siswa/i di SMP Negeri 31 Medan agar lebih memperhatikan kesehatan gigi dan mulut dengan segera melakukan perawatan pada gigi yang telah karies.

2. Diharapkan kepada pihak sekolah di SMP Negeri 31 Medan bekerjasama dengan pihak Puskesmas agar memberikan penyuluhan kepada siswa/i tentang pentingnya perawatan gigi sesegera mungkin.

\section{DAFTAR PUSTAKA}

Irma, I. 2013. Penyakit Gigi, Mulut dan THT. Nuha Medika. Yogyakarta.

Margareta, S. 2012. 101 Tips dan Terapi Alami Agar Gigi Putih dan Sehat. Sleman. Yogyakarta.

Notoatmodjo, S. 2007. Promosi Kesehatan dan Ilmu Perilaku. Rineka Cipta. Jakarta.

2010. Promosi Kesehatan Teori dan Aplikasi. Rineka Cipta. Jakarta.

Nisa, K, 2014, Hubungan Pengalaman Karies Dan Karies yang tidak DiRawat Dengan Kualitas Hidup Pada Remaja Usia 12-18 Tahun, http://repository.usu.ac.id/bitstream/123456789/6 1175/4/chapter\%20II. pdf, 9 maret 2017.

Pintauli, S., Hamada T. 2012. Мепијu Gigi dan Mulut Sehat. USU Press. Medan.
Prihastari, L, 2013, Kajian Riskesdas 2013 Kesehatan Gigi Dan

Mulut

http://www.academia.edu/9995778/Kajian Riskesdas 2013 Kesehatan Gigi dan Mulut. http://www. Riskesdas Kesehatan Gigi dan Mulut.com/2013, 9 maret 2017.

Rianti, N, 2016, Hubungan Karies Gigi Terhadap Kualitas Hidup Yang Terkait Dengan Kesehatan Gigi Dan Mulut Pada Remaja Usia 12-14 Tahun, http://file.//D:JURNAL\%GIGI/Naskah\%Publikas i, pdf, 9 maret 2017.

Setiadi, 2007. Konsep Dan Penulisan Riset Keperawatan. Graha Ilmu, Yogyakarta.

Tarigan R, 2012. Karies Gigi. EGC, Jakarta.

Tarwoto, dkk, 2012. Kesehatan Remaja Problem dan Solusinya. Salemba Medika. Jakarta. 